\title{
The Illocutionary Force behind Learning
}

\author{
Hans Drumbl \\ Faculty of Education, Free University of Bolzano, Italy \\ johann.drumbl@unibz.it
}

\author{
Renata Zanin \\ Faculty of Education, Free University of Bolzano \\ renata.zanin@unibz.it
}

Children got it, young people and adults, at least in certain areas of their activities, got it, successful language learners got it, unsuccessful language learners don't have it - the illocutionary force of speaking when learning a new language. Illocution, which Searle not without reason called 'illocutionary force,' appears as the decisive moment of the pragmatics of speech acts. Thus, illocution appears as the pragmatic foundation of speech acts in general and of speaking while learning a new language, opening ways to strategies for classroom activities biased for learning.

Keywords: illocution, language learning, learning bias

\section{Introduction}

Illocution is a concept from pragmatics, the area of linguistics that 'considers the execution of an action with the help of a linguistic utterance.' A distinction is made between different actions such as assurance, instruction, and obligation, whereby the illocutionary act represents an 'aspect,' a 'partial action,' a 'function,' a 'component,' the 'purpose' or the 'specific role' of the speech act, namely the 'purpose of an action connected with an utterance.'

On the basis of this theoretical foundation, in the 7o's a pragmatic orientation of foreign language didactics developed with impulses for communicative and action-oriented language acquisition in schools. The new focus has been on learners' activities. Learners behave 'as if' they were citizens of the country or visitors talking to competent speakers of the language. See the paradigmatic realization of the communicative approach in Strategies (Abbs and Freebairn 1975) with fascinating 'tranches de vie' of English life. This textbook, alas, did not fulfill the expectations of teachers who had embraced it with great enthusiasm. Teachers were disappointed because Strategies was received by learners with reluctance and indifference. In the absence of illocution, the exemplary life of other people apparently did not trigger any interest in learners. The speech-acts encountered in Strategies were missing the 
'fuel and fire' (Hofstadter and Sander 2013) of thinking, speaking and learning. In Italian schools there was a general return to teaching methods based on grammar and translation. Twenty years later a paradigm-shift occurred introducing syllabi with an emphasis on prosody and on prosodic skills developed in a bilingual setting (Drumbl and Missaglia 1997; Missaglia 1999; 2007).

Rethinking these issues while working together with colleagues from five different countries all working in different contexts of teaching and learning, has motivated the audacious turn which we are going to present today. Pragmatics used not in order to classify the language output - or 'input', according to the different perspective taken - but referring the categories of the pragmatic understanding of speech acts (Sprechhandlungen) to the process of learning itself. To do this, one must address the question of what learners do when they learn a new language - the actions they perform as learners. There are no actions using speech without an illocutionary force to begin with.

The result but also the starting point of scientific research is a framework of general parameters for the assessment of empirical facts. In a recent research-report which offers valuable results for concrete work in the classroom (Kersten 2019, 35), the Complex Systems Theory (Larsen-Freeman and Cameron 2008a) is cited as the theoretical foundation (p. 35):

The context of a language learning or language using activity includes the intrinsic dynamics of the learner, that is, what individuals bring to the activity, for example, their cognitive context (e.g. working memory); the cultural context (e.g., what roles the teacher and the students play in this culture); the social context, including relationships with other learners and the teacher; the physical environment [...].

This is a list of select factors that can play a role in learning and speaking, but whose weight must be assessed in relation to other factors - not yet recognized, unknown, perhaps even unrecognizable factors.

There is a double problem of weighting and direction. In the dynamic interplay of forces, it may well be that when a particular characteristic of a student coincides with a particular characteristic of the requirement for the student's learning potential (e.g. memorizing new words, learning and remembering the pronunciation of a new word), any one specific trait might have consequences that do not occur in other learners. The methodological observation of the data cannot grasp these constellations, nor can it grasp the fact that it is only in these particular constellations that the characteristics of learners become pertaining characteristics for research on language learning. 
Our contribution is part of ongoing research on language teaching in the tri-lingual working environment in South Tyrolean kindergarten and primary schools. The focus here is on the neglected points in language learning theory and practice, the main point being the core of what has been called the 'intrinsic dynamics of the learner' (see above). At the core of speaking is the motivation, or, to put it in the terms of linguistic pragmatic studies, the illocutionary force of speech acts.

The missing factor of illocution as a pertinent trait at the heart of the dynamic system proposed as the theoretical foundation for language studies is a clear sign that the theory is flawed on account of its cumulative approach and is unable to satisfy readers with hands-on experience and a holistic view of the subject-matter.

\section{Motivation and Illocution}

Larsen-Freeman and Cameron (2008a) give a list of select factors that can play a role in learning and speaking, but whose weight should be assessed in relation to other factors. Here are some factors that have not yet been sufficiently considered in scientific discourses. And they all have to do with motivation, the inner drive to achieve specific goals. A first consideration: the social and relational context may regard other facts not dealt with in research, for instance the opportunity of attending a particularly desirable and coveted school (social prestige; being with one's best friend in the same class; or having been accepted in an easily accessible school that was accompanied by the parents with a great sigh of relief, which is not unimportant to the children - for example in separation situations; the satisfaction of having passed a selective entrance examination, etc.).

Intrinsic and extrinsic motivation cannot easily be separated. Motivation is a complex basis for all learning, but it rarely shows up on the surface of behavior or it has a component that does not appear on the surface and cannot be observed. There is a striking analogy to the deep motivation in speaking, the illocution that triggers all further consequences of action.

Second, the 'plateau' problem (Richards 2008; Birdsong 1992; 2005; 2007; 2009): When learning and speaking, two basic attitudes of learners can be distinguished, which experienced teachers know from their own experience, but are rarely recognized as pertinent factors. In fact, language learners sometimes reach a 'plateau' in second-language competency, a point at which their L2 skills are (or seem) good enough for routine communication, giving them immediate satisfaction and, in some cases, acting as a threshold beyond which they do not easily develop further skills as foreign language 
speakers. In contrast, there is learning, which does not aim at a predetermined (low) level of achievement. This basic dichotomy is already proven in the acquisition of the first language. This phenomenon of 'late talkers', who speak 'perfectly' without the tedious little steps before they master the language to some extent, is a pattern of behaviour that can also be verified at an advanced age in second language acquisition. These are isolated cases.

Many other cases show a different behaviour, as Wolfgang Klein (2007, 13940) recalls with great empathy:

We have begun to investigate which of the above characteristics that we have to learn, pronunciation, morphology, etc., is particularly difficult, and now something very peculiar emerges: a student who is motivated to do so can learn each of the characteristics studied so far in such a way that native speakers cannot distinguish him from other native speakers. This applies to pronunciation, morphology, syntax, whatever has been studied. Students can learn it perfectly - but they don't. Or, more generally, adults, at least at this age, can learn a second language perfectly, perfectly always in that sense, as not distinguishable from native speakers, but they do not. That's a very mysterious circumstance that can't really be explained.

\section{Resonance}

In a review, the bias derived from a - false - basic assumption becomes evident. We call it the 'ditch'-bias, the influence of a metaphorical evaluation of an important factor which presumably prevents progress in learning a new language, leading to fossilization.

Rather than taking a cross-sectional, and therefore static view as this, a complex systems approach can plot the path of individual growth and variation across a time-scale (Larsen-Freeman and Cameron 2008[b], 245). Indeed, since 'every organism is changing and determining what is important in its world-creating and remaking the world in which it lives,' the explanations for fossilization must yield, in a complex systems perspective, to an acknowledgement of the 'boundless' potential to grow one's language resources, and not stop at the powerful attractor that is 'the neural commitment of the first language, and the ensuing entrenchment, [that] may lead to a deep valley or well' (142), which normally constitutes a trough in the trajectory of how an additional language develops. [Weideman 2009, 5] 
The metaphor of the protective wall or the protective deep trench has found universal dissemination. Larsen-Freeman and Cameron (2008b) have introduced a fascinating preamble to their book asking the question 'What if?' We adopt this formula too and ask: 'What if the deep-valley-metaphor is flawed not just by its own incongruency but by a convincing alternative view on neural organization of languages in the human brain?' After all, the answer to the question of the coexistence of several languages in the human brain could be a different one. The separation of languages in the brain does not have to take place negatively, through a deep gulf according to the almost warlike metaphor that suggests a need for protection. The separation can be achieved functionally through an increased activity of the currently used language, by the fact that the 'resonance,' the connection, the calling up of the 'familiar' elements of the language is activated more intensively and thus the words and sounds of the chosen language are addressed and called in a privileged way compared to the other languages in the brain. There is a kind of competition for resources. The theoretical model underlying this picture is the 'Competition Model' (Bates 1999; MacWhinney 1987; 2005; Hernandez, Li, and MacWhinney 2005).

\section{Rich Language Input}

Theories committed to the paradigm of emergence, resonance and networking recognize the decisive moment in the competition for the distribution of resources. From this constellation of competition for cognitive resources a winner emerges. Thus Elizabeth Bates (1999) writes in her essay 'On The Nature and Nurture Of Language,' in which she sets the course for the competition model she proposes, the potential of which is becoming more and more apparent. 'In many ways, Bates and MacWhinney were pioneers of systemsbased models for language' (Hirsh-Pasek and Michnick Golinkoff 2008, 2). The basics for this model go back to the early 80s: First, the competition model proposed by Bates and MacWhinney (1982) suggested that children develop language syntax by attending to both grammatical and semantic cues in the input. This groundbreaking work not only enabled researchers to predict how multiple cues might work together to explain language at any given point in time, but also sparked cross linguistic studies and the examination of individual differences in both typical and atypical children over time. (HirshPasek and Michnick Golinkoff 2008, 2)

In an article that builds on the fundamental work of Bates and explores these findings specifically for second language acquisition, this view of the language and the consequences for language learning in kindergarten and 
school are described in the following way (Hernandez, Li, and MacWhinney 2005, 18):

When the child's two languages are roughly similar in dominance or strength, each system generates enough system-internal resonance to block excessive transfer. However, if one of the languages is markedly weaker, then it will not have enough internal resonance to block occasional transfer. The situation is very different for $L_{2}$ learners, since the balance between the languages is then tipped so extremely in favor of L1. In order to permit the growth of resonance in L2, learners must apply additional learning strategies that would not have been needed for children. These strategies focus primarily on optimization of input, promotion of $L_{2}$ resonance, and avoidance of processes that destroy input chunks.

The didactic implementation of these guidelines for $L 2$ acquisition in kindergarten and primary school therefore can be based on the following application-oriented principles:

- L2 learners must apply additional learning strategies. In contrast to first language acquisition, learners of a foreign language must employ additional learning strategies in order to compensate for the imbalance between the two resonance spaces. These strategies focus primarily on optimization of input.

The input, i.e. the contact with the foreign language, must be optimized within the framework of a well-considered syllabus especially with regard to this act of compensation. Preference should be given to linguistic elements that are already organized in chunks and that are presented and learned in a targeted manner in accordance with their further 'elective affinities' during use.

- Promotion of $L 2$ resonance. This may include the task of providing for language use situations that require frequent and rapid code switching. In order to practice real code switching and not speaking with a constant reference to the first language (the way many Italian students deal with the foreign language), clear boundary signals in the form of untranslatable elements such as phraseologisms should be given a privileged place in the exercise.

- Avoidance of processes that destroy input chunks. This could be achieved, in a first approximation, by rigorously avoiding spontaneous transla- 
tions. Paradoxically, the best way to do this is to provide students with an idiomatic and stylistically sophisticated translation in a first step, and then to make all further steps independent of the translation. (Drumbl 2009, 79-80)

The image of language processing distilled from extensive research, which has its functional pivotal point in the concept of resonance, represents a precise framework which can be combined with the groundbreaking studies by Weitz (2015) and Kersten (2019) on rich language input.

\section{The Learning Bias}

After long and intensive discussions about the most diverse aspects and critical points of foreign language teaching, a broad consensus has emerged which regards the role of the teacher as a decisive factor. The linguistic performance of the teacher is thus at the center of a research interest that needs to be redefined. A helpful instrument here is the experience gained in bilingual teaching, which is captured by the term 'input quality observation.' The following chapter is part of a research project at the University of Bozen/Bolzano, conducted by Renata Zanin. The theoretical, not to say speculative character of this chapter is intended to draw a clear distinction between aspects of language learning that can be observed and those that are inaccessible to observation (Pulvermüller et al. 2006; Pulvermüller 2018).

The essence of this chapter is to distinguish two fundamentally different cognitive activities, one dedicated to the learning of new skills and the other to the use of skills already learned. Since it is about listening and speaking and learning the skills needed for doing so, which elude direct observation, the newly coined technical term 'learning bias' does not refer to biased views that exert their influence in cognitive processes, but rather distinguishes two cognitive activities from each other, one dedicated to learning - the 'learning bias' - and the other treated by the cognitive system as pure application of something already learned, i.e. listening, reading, speaking without the 'learning bias' inherent in the learning modality.

\section{Mapping of Heard Speech into Articulation Information}

From the linguistic perspective, our current project at the Faculty of Education of the University of Bolzano is based on a fine-grained concept of 'teacher talk' (Kleinschmidt 2018; Vosoughi and Roy 2012; Roy 2014). Linguistic input is the basis of language learning and linguistic contact between learners and their teachers is an essential basis of this learning process. The essence of 
this learning process is not just relevant for any single learner: 'Our ability to map sound into pronunciation - vocal imitation - is necessary for vocabulary learning, and so the existence of language' (Skoyles 1998). Sound, something a human ear has perceived, is going to be mapped, i.e. constructed by a process, into pronunciation, i.e. something that is accomplished, performed, produced by the speaker: 'Indeed, the existence of automatic verbal imitation is required for the continued cross-generational existence of language. Yet, in spite of its importance, how the brain manages to map sound into pronunciation is at present unknown' (Skoyles 1998, 167).

The answer given by this unorthodox researcher is: Mapping of heard speech into articulation information and speech acquisition (Skoyles 2010). This is a hypothesis with far-reaching consequences for our understanding of language acquisition and language learning.

The smallest units we hear in speech are phones with their characteristic features. Though we can hear the phones, they are not linked to auditoryrelated invariants. That is, we don't hear an [o:] or an [y:] and try to imitate the sound in relation to its pertaining invariants. According to the new findings, phones link to articulatory specifications. The input from a variety of speakers with different voices does not interfere with the child's capacity for imitating the sounds heard, if sounds are mapped directly into articulation. The word pronounced by the child is this one child's personal phonetic output comprehensible to all other speakers of that language.

In order to understand this two-step-process of speaking and learning to speak we can look at the newest way to map neural activities of speaking to the synthesizer, as reported in Nature 568 in April 2019: 'Recurrent neural networks first decoded directly recorded cortical activity into representations of articulatory movement, and then transformed these representations into speech acoustics. [...] Furthermore, the decoder could synthesize speech when a participant silently mimed sentences' (Anumanchipalli, Chartier, and Chang 2019).

Computer-based output of speech relies on innervation patterns for articulation from which, in a second step, the corresponding sounds are produced.

This double step has been known since Patricia Kuhl's seminal studies (Kuhl 2004; 2010), even if the consequences of this new insight were not immediately apparent. Kuhl pointed out very clearly that early childhood, intuitive and automatic speech acquisition only takes place in personal contact with a caretaker, but not when babies are observing a speaking person on the screen. If, when learning new sounds through intensive eye contact - accord- 
ing to the new hypothesis - the patterns of articulation are simultaneously transmitted by means of mirror neurons, the constraint to personal contact - observed by Kuhl - is sufficiently explained.

These findings are of particular relevance for the definition of input-strategies for language teaching in inclusive classrooms. Children with hearing impairments or attention deficits can be specifically addressed and encouraged through appropriate input strategies.

To understand the fundamentals of language learning one must address the question of what learners do when they learn a new language: the actions they perform - and the illocutionary force behind these actions - when actually learning a new language.

Learning how to speak does not consist in the imitation of sounds heard by the baby. We recognize sounds not just by the way they 'sound,' perceiving the auditory features, by which they can be recognized, but by articulatory invariants, that is, the precise way sounds are produced in our mouth. Phoneticians use a phonetic description of sounds given in terms of how the sounds are articulated and not how they sound.

Why should we bother? What does this new approach to language acquisition really mean? Does it mean something for practitioners of language teaching and for the learners themselves? What if what we hear, does not map into the pronunciation but into the articulation of the perceived sounds?

The consequences from the learning point of view are quite clear. Babies learn the first language following an innate instinct to learn. They learn, and they are able to learn languages, i.e. sounds used by their caretakers to communicate with the baby and among themselves.

This 'force' behind the arousal of attention can be considered metaphorically as an equivalent of the illocutionary force behind speaking, as the illocutionary force behind learning.

The new hypothesis takes into account several well-established facts about child-language development which have never been explained thoroughly in a common theoretical framework. To summarize John Skoyles' (1998) insights:

1. The existence of nearly eight hundred phones, when each language uses but a very small sub-set of these.

2. The fact, that newborns are able to hear the entire set of phones at disposal for all languages prior to their specialized usage of the subset of phones relevant for the language they are exposed to. 
3. Less known to the general public, but of no less importance is the fact, that animals also hear the phones used in human language.

According to Skoyles (1998), the conclusion cannot be but one: homo sapiens shares with his ancestors - including animals - the genetic predisposition for motor activation of the entire spectrum of possible sounds. That's the reason why newborns can actually start mapping and the process of mapping never ends:

The mapping of novel heard pronunciations strategically needs to be processed automatically upon all words. This is because speakers cannot know in advance that a word is unfamiliar. As a result, they can know a word is in need of input into motor output mapping only after the opportunity to do this has gone. Thus, speakers if they are to incorporate unfamiliar words into their spoken vocabulary must by default map all spoken input to ensure the needing mapping has been done.

Thus, children learn language by continuous repetition, exercising skills that need repetition to be mastered. Since the skills exercised are not the imitation of sounds, but of targets for the articulation of sounds, skills can effectively be exercised.

Through this automatic mapping process from heard sound onto the respective articulation targets, children get an incredible amount of reinforcement exercises and they learn to produce the subtleties of pronunciation of the languages they are exposed to.

Automatic ultra-fast mapping does not equal passive, idle exposure to something like some sort of passive 'immersion.' The process of learning is based on active response and on rehearsing.

\section{Notes}

Sections 1-5 written by Renata Zanin, section 6 written by Hans Drumbl.

\section{References}

Abbs, Brian, Angela Ayton, and Ingrid Freebairn. 1975. Strategies: Student's Book and Teacher's Book. London: Longman.

Anumanchipalli, Gopala K., Josh Chartier, and Edward F. Chang. 2019. 'Speech Synthesis from Neural Decoding of Spoken Sentences.' Nature 568 (7753), 493-8.

Bates, Elizabeth. 1999. 'On the Nature and Nurture of Language.' In Frontiers of Biology: The Brain of Homo Sapiens, edited by Rita Levi-Montalcini, David 
Baltimore, Renato Dulbecco, François Jacob, Emilio Bizzi, Pietro Calissan, and Viriginia Volterra, 241-65. Rome: Giovanni Treccani.

Birdsong, David. 1992. 'Ultimate Attainment in Second Language Acquisition.' Language 68 (4): 706-5.

- 2005. 'Nativelikeness and Non-Nativelikeness in L2A Research.' International Review of Applied Linguistics in Language Teaching 43 (3): 319-28.

- 2007. 'Nativelike Pronunciation among Late Learners of French as a Second Language.' In Language Experience in Second Language Speech Learning: In Honor of James Emil Flege, edited by Ocke-Schwen Bohn and Murray J. Munro, 99-116. Amsterdam: John Benjamins.

- 2009. 'Age and the End State of Second Language Acquisition.' In The New Handbook of Second Language Acquisition, edited by William C. Ritchie and Tej K. Bhatia, 401-24. Bingley: Emerald.

Drumbl, Hans. 2009. 'Die Prosodie im Sprachunterricht.' In Sprachen, Kulturen, Grenzen: Teilhabe an der Sprachgemeinschaft - ein Schlüssel zur Zweitsprache, edited by Elisabetta Bolla and Hans Drumbl, 23-60. Meran: AlphaBeta.

Drumbl, Johann, and Federica Missaglia. 1997. 'Prosodie und Inferenz in zweisprachiger Lernumgebung. Neue Ansätze für Deutsch als Fremdsprache in Italien.' L'Analisi linguistica e letteraria 5 (2): 391-418.

Larsen-Freeman, Diane, and Lynne Cameron. 2008a. 'Research Methodology on Language Development from a Complex Systems Perspective.' The Modern Language Journal 92 (2): 200-213.

- 2008b. Complex Systems and Applied Linguistics. Oxford: Oxford University Press.

Hernandez, Arturo E., Ping Li, and Brian MacWhinney. 2005. 'The Emergence of Competing Modules in Bilingualism.' Trends in Cognitive Sciences 9 (5): 220-5.

Hirsh-Pasek, Kathy, and Roberta Michnick Golinkoff. 2008. 'King Solomon's Take on Word Learning: An Integrative Account from the Radical Middle.' In Advances in Child Development and Behavior, vol. 36, edited by Robert V. Kail, 1-29. New York: Academic Press.

Hofstadter, Douglas, and Emmanuel Sander. 2013. Die Analogie: Das Herz des Denkens. Stuttgart: Klett-Cotta.

Kersten, Kristin. 2019. 'Einflussfaktoren im blingualen Fremdsprachenerwerb.' In Sprachenvielfalt als Ressource begreifen, vol. 2, edited by Andreas Rohde and Anja K. Steinlen, 35-70. Berlin: Dohrman.

Klein, Wolfgang. 2007. 'Spracherwerb innerhalb und außerhalb der Schule.' In DA Jahrbuch 2007, 34-44. Darmstadt: Deutschen Akademie für Sprache und Dichtung.

Kleinschmidt-Schinke, Katrin. 2018. Die an die Schüler/-innen gerichtete Sprache (SgS): Studien zur Veränderung der Lehrer/-innensprache von der Grundschule bis zur Oberstufe. De Gruyter. 
Kuhl, Patricia. 2004. 'Early Language Acquisition: Cracking the Speech Code.' Nature Reviews Neuroscience 5 (11): 831-43.

. 2010. 'The Linguistic Genius of Babies.' https://www.ted.com/talks/ patricia_kuhl_the_linguistic_genius_of_babies

MacWhinney, Brian. 1987. 'The Competition Model.' In Mechanisms of Language Acquisition, edited by Brian MacWhinney, 249-308. Hillsdale: Lawrence Erlbaum.

- 2005. 'A Unified Model of Language Acquisition.' In A Handbook of Bilingualism: Psycholinguistic Approaches, edited by Judith F. Kroll and Annette M. B. de Groot, 341-71. New York: Oxford University Press.

Missaglia, Federica. 1999. Phonetische Aspekte beim Erwerb von Deutsch als Fremdsprache durch italienische Muttersprachler. Forum Phoneticum 68. Frankfurt: Hector.

- 2007. 'Prosodic Training of Italian Learners of German: The Contrastive Prosody Method.' In Non-Native Prosody: Phonetic Description and Teaching Practice, edited by Jürgen Trouvain and Ulrike Gut, 237-58. Berlin: de Gruyter.

Pulvermüller, Friedemann. 2018. 'Neural Reuse of Action Perception Circuits for Language, Concepts and Communication.' Progress in Neurobiology 160: 144.

Pulvermüller, Friedemann, Martina Huss, Ferath Kherif, Fermin Moscoso del Prado Martin, Olaf Hauk, and Yury Shtyrov. 2006. 'Motor Cortex Maps Articulatory Features of Speech Sounds.' Proceedings of the National Academy of Sciences of the United States of America 103 (20): 7865-70.

Richards, Jack C. 2008. Moving Beyond the Plateau: From Intermediate to Advanced Levels in Language Learning. Cambridge: Cambridge University Press.

Roy, Deb. 2014. 'The Birth of a Word.' https://ed.ted.com/lessons/deb-roy-thebirth-of-a-word

Skoyles, John R. 1998. 'Speech Phones Are a Replication Code.' Medical Hypotheses 50 (2): 167-73.

- 2010. 'Mapping of Heard Speech into Articulation Information and Speech Acquisition.' Proceedings of the National Academy of Sciences 107 (18): E73. https://doi.org/10.1073/pnas.1003007107

Vosoughi, Soroush, and Deb Roy. 2012. 'A Longitudinal Study of Prosodic Exaggeration in Child-Directed Speech.' In Proceedings of the 6th International Conference on Speech Prosody, vol. 1, edited by En Qiuwu Ma and Hongwei Ding, and Daniel Hirst, 194-7. Shanghai: Tongji University Press.

Weideman, Albert. 2009. 'Complex Systems and Applied Linguistics.' Southern African Linguistics and Applied Language Studies 27 (2): 229-33.

Weitz, Martina. 2015. Die Rolle des L2-Inputs in bilingualen Kindergärten: Inquiries in Language Learning. Frankfurt: Peter Lang. 